\title{
Memoria y violencia: un recorrido por algunas reflexiones y perspectivas ${ }^{1}$ Memory and violence: a journey through
some reflections and perspectives
}

Recibido: 29 de abril de 2016 - Revisado: 14 de septiembre de 2016 - Aceptado: 28 de octubre de 2016.

Nancy Palacios Mena ${ }^{2}$

\section{Resumen}

El artículo es producto de la revisión del debate sobre memoria histórica y violencia. $\mathrm{Su}$ objetivo es trazar un recorrido a manera de diagnóstico acerca del estado actual de las discusiones y las reflexiones que sobre este problema de investigación vienen realizando diversos autores en contextos espaciales diferentes. El documento recoge una contextualización histórica de los estudios sobre memoria y violencia, las discusiones que ha generado el abordaje de estudios recientes en la historia, la forma como se ha definido la memoria desde la perspectiva de algunos autores, las principales fuentes que se han venido utilizando en los estudios de memoria y algunos abordajes que se han hecho sobre la relación, memoria, episodios violentos y construcción de subjetividades.

\section{Palabras clave}

Memoria histórica, violencia, subjetividad, narrativas.

\begin{abstract}
The article is a product of the revision of the debate on historical memory and violence. Its objective is to trace a way to diagnose the current state of discussions and there flections on this research problem that are being made by diverse authors in different spatial contexts. The document includes a historical contextualization of the studies on memory and violence, the discussions that have generated the approach of recent studies in history, the way in which the memory has been defined from the perspective of some authors, the main sources that have been used in the studies of memory and some approaches that have been done on the relation, memory, violent episodes and construction of subjectivities.
\end{abstract}

Keywords

Historical memory, violence, subjectivity, narratives.
${ }^{1}$ Artículo de reflexión vinculado al proyecto de investigación "Bojayá una masacre para no olvidar y para no repetir. Ejercicio historiográfico de reconstrucción desde narrativas e imágenes" adscrito al grupo IBANASCA de la Universidad del Tolima, Colombia.

2 Licenciada en Ciencias Sociales y magíster en Sociología de la Universidad del Valle. Doctora en Ciencias Sociales, Niñez y Juventud. Alianza CINDE - Universidad de Manizales. Postdoctorado en Ciencias Sociales, Niñez y Juventud. Centro de Estudios Avanzados en Niñez y Juventud de la alianza (CINDE) Universidad de Manizales, Colombia; Pontificia Universidad Católica de São Paulo, Brasil; El Colegio de la Frontera Norte de México (COLEF). Docente de la Universidad del Tolima y de la Universidad de los Andes. Correo electrónico: n.palaciosme@ut. edu.co; n.palaciosm@uniandes.edu.co

Para citar este artículo use: Palacios, N. (2017). Memoria y violencia: un recorrido por algunas reflexiones y perspectivas. Civilizar Ciencias Sociales y Humanas, 17(32), 209-228. Doi: $10.22518 / 16578953.827$ 


\section{Introducción}

El texto corresponde a un estado del arte o artículo de revisión, que sistematiza y analiza las reflexiones teóricas que se han revisado en el marco de un ejercicio historiográfico de reconstrucción de la memoria desde narrativas de los acontecimientos acaecidos en Bojayá, Chocó, en el 2002 . Otros productos de dicha investigación, no incluidos en este trabajo, analizan procesos de construcción de subjetividades de algunos sobrevivientes y las condiciones de vida actuales, de familias que se quedaron viviendo en Quibdó y no retornaron a Bojayá. En el artículo se hace una revisión de la relación entre la memoria y la historia; el texto no se detiene en los acontecimientos violentos ocurridos en Bojayá, se centra en la indagación teórica realizada en el marco de la investigación ya enunciada. Dicha revisión sirvió para iluminar los datos empíricos que hacen parte de los otros productos de investigación nombrados anteriormente. La fundamentación teórica a la que nos referimos se hace desde una de las tendencias actuales de la historia, la recuperación de la memoria histórica; en el marco de esta investigación, se entiende por memoria una reconstrucción siempre filtrada por conocimientos adquiridos con posterioridad, por la reflexión que sigue el suceso, por otras experiencias que se superponen a la originaria y modifican el recuerdo. Porque, en consecuencia, la memoria es una visión del pasado siempre matizada por el presente.

La primera parte del texto es una reflexión sobre la emergencia de la categoría memoria histórica y su conceptualización, posteriormente se contextualiza el surgimiento de los estudios de memoria y violencia y su importancia; seguidamente se analizan algunas de las fuentes que se han utilizado en los trabajos de investigación sobre estos temas; finalmente, y a manera de conclusión, se reflexiona sobre la memoria, la violencia y la construcción de subjetividades en sobrevivientes.

\section{Historia y memoria}

\section{La memoria y los estudios de histo- ria del presente.}

Una de las tendencias actuales de la historia es la recuperación de la memoria. Los trabajos de reconstrucción de la memoria histórica hacen parte de los estudios historiográficos que se vienen desarrollando en las últimas décadas. Según Hobsbawm (2005), hacen parte del campo de estudios culturales, en los cuales se ha propuesto superar la dicotomía relativismo universalismo; estudios en los cuales se desea una investigación racional sobre el curso de las transformaciones humanas, que consideren la historia como una tela invisible donde se interconectan todas las actividades humanas.

La memoria es la vida, sostenida por los sobrevivientes, la historia es la reconstrucción siempre problemática e incompleta de que acontece. La memoria tiene su raíz en lo concreto, en el espacio, el gesto, la imagen y el objeto (Cosci, 2011, p. 30).

Para Olick (1998) los estudios historiográficos de la memoria representan un intento por lentificar el procesamiento de información, un intento de exigir un espacio de anclaje en un mundo de una heterogeneidad desconcertante $\mathrm{y}$, a menudo, de no sincronía y de saturación informativa. Para este autor, los estudios de memoria se fundamentan en la relación entre el esplendor narrativo y las realidades concretas de las prácticas sociales (p. 106). Desde comienzos de la década de 1980, los estudios vinculados a la memoria ocupan un lugar central en los debates sobre la cultura en el mundo actual, porque se ha suscitado un gran interés por rescatar el pasado para la renegociación del presente y la proyección del futuro (Schwarzstein, 2002). La pasión memorialista es motivada, según Pierre Nora (1994, Citado por Cuesta, 1998), por el "recalentamiento del presente", es decir, por la aceleración de procesos históricos que nuestra 
cultura quiere recordar y en algunos casos, no repetir. Traverso (2007), por su parte, justifica la obsesión memorialista de nuestros días como resultado del declive de la experiencia transmitida, en un mundo que ha perdido sus referentes, ha sido desfigurado por la violencia $\mathrm{y}$ atomizado por un sistema social que borra las tradiciones y fragmenta las existencias.

En consecuencia, la explosión de los estudios de reconstrucción de la memoria sobre acontecimientos violentos, se constituye como uno de los campos más prominentes de la historia del presente. Según Julio Aróstegui (2004), esta nueva perspectiva historiográfica es la transcripción de la historia vivida, entendida como historización de la experiencia. Para Cuesta (1993), la historia del presente no tiene como objetivo añadir una nueva época a la división cronológica convencional de la historia, sino completar la historia contemporánea con la aproximación a su propia coetaneidad; desde este punto de vista, la historia del presente es una perspectiva dinámica y móvil, que se identifica con el periodo cronológico en que desarrollan su existencia los propios actores e historiadores.

La historia del presente tuvo su origen en el último cuarto del siglo XX, en el afán de un sector de la historiografía francesa por diferenciar las investigaciones de lo muy contemporáneo, respecto de la historia anterior a la Segunda Guerra Mundial; planteando nuevos elementos de análisis como el testimonio, la memoria en sus múltiples usos históricos, políticos y sociales; y el acontecimiento enfrentado a la historia de larga duración.

Es cierto que en toda época, desde Tucídides a los cronistas medievales o modernos, ha existido una atención muy marcada por la historia vivida, pero con la institucionalización de una disciplina histórica con pretensiones de cientificidad a mediados del XIX, lo coetáneo fue expulsado del discurso historiográfico oficial. Sólo en la modernidad, en el momento en que se pretendió dar a la Historia un estatuto científico determinado y preciso, se consideró que el transcurso de un determinado período de tiempo, era imprescindible para que el historiador pudiera aplicar su método crítico de forma eficaz. La superación del positivismo, que había optado en exclusiva por un horizonte de pasado, allanó el camino a la historia de nuestra contemporaneidad, favorecida por la quiebra del fetichismo del documento escrito, y por la incorporación de nuevas fuentes y métodos al quehacer historiográfico (Aróstegui, 2004, p. 329).

La comprensión de la historiografía del presente es compleja, por cuanto se ocupa de un periodo en construcción que crea el pasado y el futuro a la vez: es el tiempo real de la experiencia vivida por el hombre, desde el cual imagina el futuro y se representa el pasado. Aróstegui (2004) considera que la historia del presente es una perspectiva arriesgada por la proximidad y la trascendencia de los temas estudiados, por ser un terreno atractivo para la mayor parte de las ciencias sociales: la sociología, ciencia política, economía, y por la incidencia de una demanda social que pone al historiador ante un ineludible deber cívico. Lo anterior según el autor, "deriva en un peligro de banalización, al ser la historia del presente, la vedette de la producción historiográfica actual y un campo susceptible de ser invadido por divulgadores de calidad y rigor muy variables" (p. 28).

Por ser objeto de estudio de la historia, la memoria es instruida por esta. La historia según Ricoeur (2000), tiene la labor crítica de ejercer una instrucción terapéutica que la ayuda a aumentar la distancia respecto de los usos y abusos. Dicha labor crítica, incluye el examen de las fuentes para distinguir lo verdadero y lo falso, y a establecer tipologías de los malos testimonios. En esta misma línea Yerushalmi (1998) argumenta que contra los militantes del olvido, los traficantes de documentos, los asesinos de la memoria, y los conspiradores del silencio; el historiador solo, animado por la pasión de los hechos, de las pruebas, de los testimonios, que son alimentos de su oficio, puede velar y montar guardia. 
Los estudios de memoria que referimos en la mayor parte del texto, podríamos ubicarlos en lo que se ha llamado las "luchas por la memoria" y han estado ligados a variados intereses; por un lado, a la decisión de legar a las próximas generaciones registros de acontecimientos violentos que se consideran deben conocer y, por el otro, al interés que generan dichos acontecimientos en los académicos y en algunas instancias institucionales. Sin embargo, es innegable también el gran debate que han generado los estudios de ciertos acontecimientos de la historia reciente, por la falta de una distancia temporal "necesaria" para abordar los temas del pasado (Traverso, 2007). Si bien no se ha establecido con exactitud el periodo de tiempo que debe haber entre la ocurrencia de un hecho histórico y el tiempo propicio para que este sea analizado, ha existido implícitamente la creencia que debe haber un periodo prudencial que sirva de enfriamiento entre el historiador y su objeto de estudio para que éste se libere de las pasiones del presente de su trabajo profesional; en el texto titulado El pasado cercano en clave historiográfica, Franco y Levín (2007) se acercan al debate con planteamientos como los siguientes:

El problema de la distancia temporal no puede cancelarse tan sencillamente. Por un lado, porque existe esta relación transferencial entre el historiador y su objeto de estudio que es constitutiva de su práctica y que sin duda interviene, no necesariamente de un modo consiente, en la elección de sus problemas, preguntas, abordajes, metodologías, y marcos conceptuales. Por el otro, porque al tratarse de objetos de estudio de gran presencia y relevancia en las sociedades actuales, el historiador se encuentra presionado por una sociedad expectante y vigilante de su trabajo. Por ejemplo, el enorme campo de investigaciones sobre las luchas por la memoria en América Latina se nutre tanto del interés académico y público como de la empatía que muchas veces esas causas generan en el investigador. Esto muestra hasta qué punto el problema de la falta de distancia histórica existe, y aunque ya no pueda considerarse un impedimento para investigar sobre el pasado cercano debe ser atendido como un problema que los historiadores deben enfrentar (p. 4).

Para Franco y Levín (2007), diversas prácticas sociales y un número creciente de disciplinas y campos de investigación, hacen del pasado cercano su objeto de estudio e incluso a veces su excusa y medio de legitimación. Estas autoras subrayan que la memoria como práctica colectiva de rememoración, intervención política y construcción de una narrativa impulsada por diversas agrupaciones e instituciones surgidas tanto de la sociedad civil como del Estado, tiene la voz cantante en este vuelco hacia el pasado reciente.

También señalan que el problema de investigación al cual se han volcado la mayoría de estos estudios es sin duda la violencia, los estudios de memoria del pasado reciente han centrado su atención en temas y problemas vinculados a procesos sociales considerados traumáticos: guerras, masacres, genocidios, dictaduras, crisis sociales y otras situaciones extremas que amenazan el mantenimiento del lazo social y que son vividos por sus contemporáneos como momentos de profundas rupturas y discontinuidades tanto en el plano de la experiencia individual como colectiva.

Sin duda, otro aspecto que ha influido en la vitalidad de la categoría memoria, lo constituye la abundancia y la diversidad de las fuentes de que se dispone hoy en las ciencias sociales en general y en la historia en particular. En un contexto de incremento de las fuentes históricas y puesta en cuestión de las jerarquías tradicionales, la memoria se inscribe como un nuevo lugar de trabajo para la escritura del pasado.

En el caso colombiano la necesidad y la decisión de comprender y explicar las causas del conflicto armado, sus protagonistas, sus efectos, y principalmente la decisión de evitar la repetición de la violencia que ha marcado 
la vida del país en las últimas décadas, ha catapultado a la memoria como una categoría sobre la que están reflexionando y produciendo aportaciones investigadores independientes, instituciones estatales, ONG y comunidades de base. La memoria de la violencia abre preguntas de investigación y responde otras, para Jaramillo (2010) interrogantes como qué se dice y cómo, quién dice, y desde qué posición social, histórica y política, serán resueltas si en los trabajos de reconstrucción de la memoria pública, privada, oficial, no oficial, hegemónicas y subalternas, se escudriñan los sentidos y los lugares de enunciación de los archivos y de los testimonios. Lo anterior es necesario para avanzar en la comprensión de los pasados recientes de violencia, en los procesos fallidos o inconclusos de reconciliación y de justicia, y en las experiencias exitosas para reconocer la pluralidad de los significados políticos de lo que ha acontecido desde la voz y experiencia de los agentes:

Desde esta perspectiva, es necesario tener en cuenta el sentido que cobra para los distintos sectores, lo que debe ser conservado u olvidado en una nación, en unos individuos, en unos lugares de la memoria. Es necesario reflexionar sobre lo que debe ser protegido ante el peligro de desvanecerse con el paso implacable del tiempo, o aquello que se ha ocultado por razones e intencionalidades políticas (pp. 61-62).

Tal y como señala Jelin(2002), la memoria funciona como estímulo en la elaboración de la agenda de la investigación histórica a la vez que la historia permite cuestionar y probar críticamente los contenidos de las memorias.

Compartimos la postura de Montoya y Arango (2008), quienes sostienen que la conjugación de esfuerzos de enunciación, de recuperación de un habla silenciada por la violencia, es una tarea que en Colombia es urgente: "Un pasado de violencia del que no se aprende y que además no parece dispuesto a detenerse, aparece como un argumento constitutivo de una so- ciedad cifrada por huellas y marcaciones traumáticas, incapaces de revertir lección alguna de la imaginación del porvenir" (p. 192). La categoría memoria es crucial en la reconstrucción de hechos de violencia que vinculan acontecimientos traumáticos, aniquilación y sufrimiento colectivo. Para La Capra (2001), eventos traumáticos, tienen un efecto mayor en la víctima, pero de diferentes maneras también afectan a todos los que entran en contacto con él: el perpetrador, el colaborador, el testigo.

\section{¿Qué se está entendiendo por me- moria?}

Si bien como anunciamos en el apartado anterior, vivimos un florecimiento de los trabajos de memoria, se hace necesario precisar cómo se está entendiendo el término, porque se puede estar haciendo alusión a muchas cosas con el mismo nombre. Para Tafalla (1999) cuando filósofos y teóricos hablan de memoria pueden estar haciendo referencia a cosas diferentes, que guardan entre sí estrechas y complejas relaciones; la noción de memoria puede aludir a una dimensión epistémica, que señala objetos, discursos, recuerdos, representaciones individuales y grupales y al campo disciplinar que se encarga de su estudio, pero la noción también puede aludir a la capacidad y al deber ético de extraer de la masa informe de los muertos individuales y las historias sustraídas para restituir, por más imposible que resulte esa tarea, las identidades abolidas y ocultas por regímenes de exterminio industrializado.

Lo que frecuentemente ocurre según Tafalla (1999) es que los usos de la memoria a los que se alude resulten muchas veces entremezclados y con muy difusas líneas de separación, pero es importante desatacar en cualquiera de los casos, la dimensión política y ética que involucran los estudios de memoria, igual de valioso que mantener vivo el legado de los pueblos, sus prácticas, expresiones y percepciones también lo es, la oportunidad de recordar y rendir tributo a aquellos que la violencia obligó a desapare- 
cer. Sobre este punto, también son valiosos los aportes de Herrera, Ortega, Cristancho y Olaya, y Alejandro Castillejo. Para los primeros, algunas investigaciones identifican que la memoria encarna la posibilidad de revitalización del pasado, sentido en el cual puede ser un arma de doble filo, pues a través de los relatos, se hace un procesamiento de lo sucedido en términos liberadores, pero también puede significar la reproducción de los hechos violentos que sitúan al sujeto en el lugar de la re-victimización (Herrera et al., 2014, p. 52).

Castillejo (2005) subraya que, dependiendo del contexto, ciertas prácticas investigativas causan daños a las comunidades donde son usadas. Según este autor, en torno a la ocurrencia de fenómenos violentos, se ha formado en la academia una especie de industria de la extracción. Los expertos en extracción (académicos de diferentes disciplinas) aprovechan el vacío dejado por la falta de reconocimiento que muchos excombatientes y sobrevivientes sienten sobre su experiencia. Dicha industria de la extracción está asociada a la recolección de testimonios de eventos traumáticos, con el fin de entender el fenómeno de la violencia y las consecuencias que esta tiene sobre los individuos y las comunidades:

En primer lugar, una amplia variedad de expertos en trauma, psicólogos de diferentes persuasiones teóricas (desde expertos en el «síndrome de post-estrés traumático» hasta los psicoanalistas), antropólogos, politólogos, sociólogos y trabajadores sociales. En segundo lugar, tenemos un puñado de diseminadores de las experiencias traumáticas, como los periodistas y otro tipo comentaristas. El primer grupo está más preocupado por lo que denominan «la producción del saber», según sus intereses teóricos, sobre las diferentes dimensiones del «trauma». El segundo grupo está más interesado en realizar un archivo público de tal manera que el pasado no se repita. Estos intermediarios son responsables de reproducir y en cierta medida, reciclar las experiencias personales del pasado traumático de un individuo para la sociedad en general, a través de diferentes productos, como los ensayos académicos, los comentarios en los periódicos y documentales (p. 51).

Los cortos espacios de tiempo de las agendas investigativas, la limitada financiación de las mismas y la falta de compromiso de largo plazo con las comunidades, son según Castillejo, las principales causas de la re-victimización de los participantes de algunas investigaciones; pues muchos de los sobrevivientes se vuelven reticentes a participar en otros estudios, perpetuando con ello el silencio histórico y las formas particulares de violencia.

A las alertas sobre los cuidados éticos que hay que tener con los estudios de memoria, hay que sumarle las alertas en lo relacionado con la influencia del poder (las élites, los estados $\mathrm{u}$ otros grupos) en la producción de lugares $\mathrm{y}$ discursos de memoria para favorecer sus intereses. Jacques Le Goff (1991) llama la atención en este aspecto, afirmando que en las sociedades desarrolladas, los nuevos archivos orales y audiovisuales no se han sustraído a la vigilancia de los gobernantes, aun cuando estos no son capaces de controlar esta memoria tan estrechamente; como en cambio logran hacerlo con nuevos instrumentos de producción de memoria, tal como la radio y la televisión. Para el historiador francés, la memoria, a la que atañe la historia, que a su vez la alimenta, apunta a salvar el pasado solo para servir al presente y al futuro. Se debe actuar de modo que la memoria colectiva sirva a la liberación, y no a la servidumbre de los hombres. En este orden de ideas, Jaramillo (2010) muestra que en América Latina, no todos los actores y agentes deseados han participado en la re-construcción de la memoria; muchos han sido silenciados en esta tarea, y hoy en día, muchos siguen traumatizados y temerosos de recuperar sus pasados. Según Jaramillo, a lo anterior hay que agregar que varias experiencias de recuperación y mantenimiento de las luchas por la memoria, la verdad y la justicia, tampoco han sido debidamente reconocidas y legitimadas. 
Desde la perspectiva de Husson (2000), "la memoria es la forma en que una colectividad recuerda su pasado y busca proporcionar una explicación al presente para darle sentido" (p. 1). Para Traverso (2007), "la memoria es una construcción, siempre filtrada por conocimientos adquiridos con posterioridad, por la reflexión que sigue al suceso, por otras experiencias que se superponen a la originaria y modifican el recuerdo" (p. 71). Este autor considera que la memoria son representaciones colectivas del pasado tal y como se forjan en el presente, la memoria estructura las identidades sociales inscribiéndolas en una continuidad histórica y las dota de sentido. Según Gaulejac y Silva (2002), la memoria es una herramienta de historicidad, constituye la expresión del trabajo individual o colectivo, que puede llevar a cabo un sujeto sobre su historia en un intento por conferirse libertad, autonomía, creatividad ante las múltiples determinaciones de las que es producto (p. 31).

Blair (2002) "plantea que la memoria no es entonces ese almacén de recuerdos donde los acontecimientos del pasado se queden fijos e inalterados para luego ser rememorados" (p. 23). Ella es, más bien, una construcción que se elabora desde el presente $\mathrm{y}$, fundamentalmente, desde el lenguaje. Son varios los aspectos a destacar en las anteriores definiciones: la función de la memoria como puente para ayudarnos a entablar vínculos entre lo público y lo privado, el valor de la memoria en la recuperación del pasado, la importancia que tiene dar sentido y significado a ciertos acontecimientos, la inclusión de las vivencias del presente en aquello que se está recordando, el papel preponderante de los seres humanos para dar sentido a lo que viven, la importancia de la memoria en la construcción de identidades y subjetividades políticas que se constituyen en detonantes de acciones políticas tanto individuales como colectivas.

La memoria puede aludir tanto a la capacidad de conservar o retener ideas previamente ad- quiridas como, contrariamente, a un proceso activo de construcción simbólica y elaboración de sentidos sobre el pasado. Por otro lado, la memoria es una dimensión que atañe tanto a lo privado, es decir, a procesos y modalidades estrictamente individuales y subjetivas de vinculación con el pasado, como a la dimensión pública, colectiva e intersubjetiva. Más aún, la noción de memoria nos permite trazar un puente, una articulación entre lo íntimo y lo colectivo, ya que invariablemente los relatos y sentidos construidos colectivamente influyen en las memorias individuales (Franco \& Levín, 2007, p. 7).

Todo lo anterior, explica de alguna manera el vigor y la fuerza que cada día han ido tomando los estudios de la memoria en la historia reciente, sin embargo, como en muchos campos de estudio de las ciencias sociales, no pocos han advertido sobre los cuidados que hay que tener en el abordaje de estos estudios. Las principales alertas se han hecho advirtiendo los peligros que generan la banalización y la sacralización de la memoria. En cuanto a la primera, el centro de las críticas ha sido el tratamiento que se ha dado desde los medios de comunicación y la forma como desde el mercado se han dado ciertos usos a la memoria.

En cuanto a la segunda, las críticas han girado en torno al uso de anacronismos históricos, al acceso de ejercicios de reconstrucción de memoria con poca o ninguna reflexión y al tratamiento de excepcionalidad y exclusividad que se ha dado a algunos acontecimientos. Según Blair (2002), si se da el carácter de sagrado a un acontecimiento, no se determina su especificidad y, por ende, se dificulta establecer su relación con los demás, el carácter sagrado, exige aislarlo del resto y creerlo único. La banalización consiste según esta autora, en superponer el pasado al presente, en asimilarlos, sin más, con el resultado de desconocer uno a otro.

Para Blair (2002), se escuchan voces encontradas frente a los beneficios de la memoria. No porque no haya necesidad de reconocer, sino 
porque la relación que el recuerdo establece con el olvido no es de oposición directamente. En los abusos de la memoria, Todorov (2000) enfatiza en que no podemos ni sabemos recordarlo todo, por lo tanto, debemos reflexionar sobre el pasado y enfrentarlo cuidando de no dar un culto excesivo a la memoria. Argumenta además que conservar la memoria del pasado es útil, no para exigir reclamación por los daños causados sino para evitar que dichos hechos vuelvan a repetirse.

Como se planteó anteriormente otro ámbito de la crítica a la reconstrucción de la memoria se ha centrado en el papel que ha jugado el mercado. Al respecto, Huyssen (1999) destaca que el boom industrializado de la memoria marca el éxito editorial de los relatos de violencia y tortura, este éxito oculta el horror con deleite consumista, no hay irrepresentabilidad ni impresentabilidad con una memoria completamente expuesta, divulgable y comunicable por redes del consumo informativo. Martha Cabrera (2006) se ha ocupado del tema para el caso de Colombia y ha concluido que el papel de los medios de comunicación y particularmente de la televisión, ha sido fundamental en la percepción de la violencia. Para Cabrera, a diferencia de otras experiencias como las de Sudáfrica o Argentina, el papel de los medios de comunicación no ha contribuido a constituir un relato integrador, sino que, por el contrario, las narrativas de terror local se vinculan con las del terror nacional, sin que adquieran un significado global distinto al de la persistencia carácter cíclico de la violencia:

El modelo de la formación de la memoria que articula la violencia política y que persiste en Colombia, es entonces necesariamente sacrificial. Este modelo tiene un eje performativo basado en la coerción y la amenaza que se visibiliza mediante el espectáculo del miedo. En el ámbito narrativo, el modelo sacrificial condensa la multitud de memorias y es la violencia quien asume el papel del aparato historiográfico. La memoria formada mediante un modelo sacrificial ofrece pues, enormes retos en la construcción de un relato histórico que rompa con la cualidad mítica, pesadillesca de la violencia (p. 51).

En este pequeñísimo balance sobre las formas como se está trabajando y se está entendiendo la memoria, cabe incluir el llamado de atención que hace Jaume Aurell (2006) al plantearnos que vivimos una angustiosa aceleración e intensificación del presente, propia de nuestro tiempo que lleva consigo, una obsesión compulsiva de la memoria. Según Aurell, "el presentismo se ha insertado de modo estable en la percepción del pasado de las sociedades contemporáneas y la lectura que se hace de los recuerdos está impregnada de los valores del presente, y por lo tanto condicionada por él" (p. 163). Desde la postura de este autor, la lectura intencionada del pasado se radicaliza, porque se sublima el proceso de subjetivación, al ponerse énfasis en la misma memoria, más que en el objeto de esa memoria, esto explica que las reivindicaciones de la memoria vienen ahora determinadas por las necesarias, pero insuficientes reparaciones históricas de dolorosos hechos del pasado. Para Aurell, la memoria tiene una función social evidente y por este motivo es preciso tener presente las dimensiones morales que comporta su orientación en la vida de los pueblos.

\section{El contexto del surgimiento de los estudios de memoria y violencia y su importancia.}

La reflexión sobre la reconstrucción de memoria de episodios de violencia no es nueva, como se enunció al principio del texto, dichas reflexiones hacen parte del debate historiográfico desde los años 70 y 80 , posterior a las críticas que se le hicieron a la historia de las mentalidades y el surgimiento de otras posturas como el giro lingüístico, el giro cultural y más recientemente el giro subjetivo. Si bien estas nuevas posturas no son exclusivas de la historia, sin duda han impactado la forma como historiadores de muchos contextos han abordado sus objetos de estudio. Pues bien, los 
estudios de reconstrucción de memoria histórica que han surgido en este momento, se han caracterizado por ser trabajos con los cuales se busca comprender mejor los procesos sociales de construcción, apropiación y conservación de la memoria de las comunidades sobre los sucesos que viven y sobre todo aquello que constituye su identidad. Dichos trabajos han estado en diálogo permanente con la relevancia que viene teniendo la relación entre escritura e historia, la narrativa histórica y los intentos por reivindicar y recuperar el relato histórico; en un enfoque en el que la narrativa apunta a un mayor rigor de la exposición histórica a través de una estructura coherente del relato.

En el trabajo titulado Memoria y narrativa: la puesta del dolor en la escena pública, Elsa Blair (2002) señala que la reflexión sobre la guerra, en relación con el dolor y la memoria se puso sobre el tapete en América Latina durante los años 80 con el tránsito entre las dictaduras militares y los gobiernos democráticos. Los gobiernos civiles tuvieron no solo la tarea de recuperar una legitimidad política, sino también la de resolver un drama moral de inmensas proporciones: los asesinatos, las muertes selectivas y las desapariciones alcanzaron cifras alarmantes y con ellas, las sociedades se enfrentaron al dolor producido por esos eventos.

Pero un punto central a ser destacado en el contexto histórico en el cual se reavivan los estudios de memoria, es la importancia que en él juegan los actores sociales, según Jelin (2003), a partir de las preocupaciones políticas por la democracia, de los desarrollos de los nuevos movimientos sociales y su mirada sobre la cotidianidad, del pensamiento sobre la ciudadanía y la constitución de las subjetividad ciudadana, abonados por la práctica política de lucha de los movimientos de derechos humanos:

Se ha implantado en la región un nuevo marco interpretativo de la esfera pública, de la relación entre Estado y sociedad, y de los mecanismos y articulaciones entre el plano de las condiciones materiales, las institucionales, la subjetividad y el nivel simbólico-cultural (p. 5).

En consecuencia, en lo concerniente a las condiciones socio-históricas en las cuales se produjo el surgimiento de los estudios de memoria, son dos los puntos coincidentes entre Jelin y Blair que queremos destacar; la urgencia social por la restauración de la democracia y sus principios fundamentales, y la gran dinámica que han adquirido las acciones de quienes fueron afectados por hechos violentos y por la sociedad en general, en una aclamación unánime por el respeto por los derechos humanos.

Desde la perspectiva de Jelin (2003), las luchas políticas por arreglar las cuentas con el pasado tuvieron como intención, en el período postdictatorial, la búsqueda de la verdad, la búsqueda de justicia, la intención de encontrar algún sentido al pasado doloroso. Las iniciativas fueron de movimientos de derechos humanos, abogando por el reconocimiento de lo ocurrido, tanto en el plano del estado como en el de la subjetividad. Las luchas por las memorias y por el sentido del pasado se convierten aquí, en un nuevo campo de la acción social en la región, y también en un nuevo campo de investigación social, con características propias: la complementariedad de distintos enfoques y disciplinas necesarias para un abordaje centrado en el punto de convergencia entre patrones institucionales, subjetividades y manifestaciones en el plano simbólico.

Adicional a lo anterior, hay dos ejes de la discusión anterior que también merecen ser destacados: el primero, es el planteamiento de Hirch y Díaz (2010), según el cual, "a partir de 1995, los trabajos sobre memoria introducen como un nuevo ingrediente la necesidad de evitar el olvido desde reflexiones conducentes a búsqueda de sentido sobre el pasado y la repetición de los actos de violencia" (p. 113). El segundo planteamiento es el de Daniel Pécaut (2003), "quien afirma que el surgimiento de la memoria está ligado al desmoronamiento del 
Estado-nación en los planos concreto y simbólico" (p. 113). Desde la postura de Pécaut la explosión de otras memorias debilita la hegemonía de la memoria nacional, multiplicación de voces no necesariamente en sintonía con la versión nacional y tradicional del pasado, es el escenario para que afloren otras subjetividades cuyas adherencias no son con lo nacional sino con el género y la etnia, por ejemplo.

Desde la postura de Serna (2009), afirmaciones políticas sobre el estatuto de la memoria le concedieron lugares diferentes a la amnesia y a la anamnesis. La amnesia fue considerada un estado permanente inherente a las contradicciones y conflictos sociales, que tenía su origen en la imposición de consciencias ajenas o falsas sobre los sujetos o agentes sociales, en detrimento de su propia naturaleza histórica, social y cultural. La anamnesis implicaba la toma de consciencia de las condiciones objetivas de la existencia social, que era en cualquier caso una consciencia histórica, social y cultural; que solo podía surgir, afirmarse o consolidarse, en medio de luchas sociales concretas que tendrían como uno de sus espacios decisivos, las instituciones destinadas específicamente a la socialización. Desde los años treinta diferentes enfoques han controvertido estas premisas, algunas con más énfasis que otras:

En primer lugar están una serie de enfoques que, en medio de sus críticas a las cegueras de la modernidad, controvirtieron el estatuto de la memoria que la sujetó a una disyunción de base y que la puso en una condición de exterioridad con relación al lenguaje. [...] En segundo lugar están una serie de enfoques que, decididos en la crítica a los totalitarismos de todos los pelambres, a los encarnados en los campos de concentración, en el gulag, en los cuarteles tenebrosos y más recientemente en los presidios extraterritoriales como Guantánamo, han controvertido la pretensión de una memoria atada a unas formas conmensuradas del lenguaje, a unas certezas absolutas soportadas sólo en la facticidad de los acontecimientos. [...] En tercer lugar están una serie de enfoques que, en medio de sus críticas a los modos de imposi- ción colonial, controvirtieron el estatuto de la memoria nutrido o surtido desde la tradición occidental. Para estos enfoques, la tradición occidental se encargó de reducir la memoria desde el momento en que impuso una falsa jerarquía donde las formas orales fueron subordinadas a las formas escritas. [...] En cuarto lugar están una serie de enfoques que, en medio de sus críticas a los procesos forzados de democratización de los Estados y de modernización de las sociedades, han controvertido el estatuto de la memoria auspiciado desde las políticas culturales. [...] En quinto lugar están una serie de enfoques que, surgidos en medio de procesos de verdad, justicia y reparación, han controvertido las concepciones que fragilizaron el papel de la memoria, que limitaron sus condiciones como instancia de conocimiento, que restringieron sus alcances o que sólo le dieron alguno a su dimensión política y que, obviamente, no le concedieron un lugar especial en el deber de justicia (pp. 19-22).

Un lugar especial en lo que podemos denominar las luchas por la reconstrucción de la memoria, lo ocupan los centros de memoria; la investigación sobre estos, realizada por Torres (2015), los define como espacios que buscan cumplir con el deber de memoria de recordar los pasados violentos en una sociedad. En este sentido, pretenden incluir voces que den cuenta de las distintas narrativas sobre el pasado que develan tensiones e intereses en lo público. Los resultados de la investigación de Torres, indican que, desde la segunda mitad del siglo XX, se ha visto un auge en la creación de museos de la memoria como parte del mandato jurídico; una política de la memoria, una comisión de la verdad o una iniciativa privada. Dichos centros buscan recordar los pasados violentos de distintos países en África, Asía, América y Europa. Sus objetivos varían según las condiciones a las que buscan dar respuesta, pero que finalmente se conectan en los objetivos que persiguen: algunos promueven luchas por los derechos humanos, otros la búsqueda de la verdad para hacer justicia, reconocer y reparar a las personas que han sufrido de cerca los conflictos y la violencia. 
En el caso de Colombia, Torres (2015) destaca el interés del Centro Nacional de Memoria Histórica por generar unos espacios de memoria que permitan la reparación y la conmemoración de las víctimas del conflicto armado, en un contexto paralelo a la búsqueda de acuerdos de paz, de la verdad, la justicia y la reparación. Sin desconocer el impacto que iniciativas privadas, comunitarias y locales han tenido. Herrera et al. (2014) destacan las apuestas del Grupo de Memoria Histórica y del Movimiento Nacional de Víctimas de Crímenes de Estado. En el primero destaca cómo a través de diversas estrategias metodológicas con comunidades, han incidido en las narrativas habituales para superar su grado de fragmentación; posibilitando mediante la interpelación crítica, narrativas emergentes que superan la rememoración de hitos aislados y amplían la comprensión de los acontecimientos y de la experiencia de las comunidades sobre los mismos. Del segundo, destaca cómo desde su creación ha documentado la crisis humanitaria del país; reconociendo los crímenes de lesa humanidad en pro de la reivindicación y reparación integral de las víctimas, así como la defensa de sus derechos en materia de justicia y acceso a la verdad.

Hay que rescatar, sin embargo, el carácter polémico de la construcción de la memoria enunciado por Jaramillo (2010), quien resalta que dicho carácter polémico se relaciona con las múltiples maneras y los diversos sentidos, a través de los cuales se recupera, gestiona, tramita o trabaja política o socialmente con la memoria. Siguiendo a Todorov, Jaramillo (2010) afirma que dependiendo de qué pasado se pretenda recuperar, en función de qué presente y con cuáles pretensiones y costos se quiera reconciliar una nación, existen buenas y malas intencionalidades políticas, morales y públicas, en la construcción de la memoria.

Otro punto de vista a incluir en la discusión sobre la influencia en la construcción de memoria, es el expuesto por el historiador Reinhart Koselleck (2006), para él la identidad y la memoria colectiva dependen fuertemente de los hablantes impregnados de ideología. Su posición personal en este tema es muy estricta en contra de la memoria colectiva; Koselleck argumenta que estuvo sometido a la memoria colectiva de la época nazi durante doce años de su vida y por ello, le desagrada cualquier memoria colectiva. Considera que la memoria real es independiente de la memoria colectiva, y su posición al respecto es que la memoria depende de las experiencias de cada uno, y nada más. Desde su punto de vista, cada sujeto sabe cuáles son sus experiencias personales y tiene derecho a mantenerlas como las ha memorizado. Para este historiador, los acontecimientos que cada uno guarda en su memoria, constituyen su identidad personal; la idea de identidad colectiva vino de las famosas siete pes alemanas. Considera que los profesores, los párrocos, los políticos, los poetas y la prensa, producen las memorias colectivas; estos la pagan, la producen, la usan, muchas veces con el objetivo de infundir seguridad o confianza en la gente. Para Koselleck (2006) eso no es más que ideología:

Así pues, la memoria colectiva es siempre una ideología, que en el caso de Francia fue suministrada por Durkheim y Halbwachs; los cuales, en lugar de encabezar una Iglesia nacional francesa, inventaron para la nación republicana una memoria colectiva que, en torno a 1900, proporcionó a la República Francesa, una forma de autoidentificación adecuada en una Europa mayoritariamente monárquica, en la que Francia constituía una excepción (p. 1).

De ese modo, en aquel mundo de monarquías, la Francia republicana tenía su propia identidad basada en la memoria colectiva.

\section{Los estudios de memoria y sus fuentes.}

Si bien en los estudios de memoria que se han venido produciendo en las últimas décadas se puede hablar de la existencia de una 
pluralidad de fuentes, también es cierto que la mayoría de trabajos han dado prioridad a los relatos orales y la construcción de narrativas, lo anterior obedece a la prominencia que en estos estudios se ha dado a las voces de las víctimas y a la reconstrucción histórica de los hechos violentos en una búsqueda por la justicia, la verdad, la reparación y la no repetición.

Aunque las fuentes orales no han sido tradicionalmente las fuentes más utilizadas en los estudios históricos, en los trabajos de reconstrucción de memoria, estas fuentes permiten una aproximación crítica sobre el pasado reciente porque contribuyen a mayores aproximaciones en la complejidad y análisis del papel de los sujetos en la sociedad (Mudrovcic, 2005, p. 115). En palabras de Dora Schwarzstein (2010), las fuentes orales, con toda la complejidad del debate sobre sus usos y las formas de emplearlas, ofrecen una posibilidad enorme para articular proyectos de diferente naturaleza para el conocimiento histórico. Desde la perspectiva de Tébar (2006), el material recopilado en relatos es singular y valioso, tanto por el contenido de la narración como por el sentido moral, es decir, los actos y las actitudes ante el contexto histórico.

El valor del relato es también resaltado por Richard (2002), al señalar que el relato logra forzar la atención sobre algo que la historia a menudo rechaza como simple índice residual; un índice carente de la generalidad suficiente para ser portador de una verdad incontrovertible. "El testimonio pone en escena una corporización biográfica que desvía el orden general de las verdades objetivas del recuento histórico" (p. 192). A este grupo de autores que recogen el valor de los relatos en estudios de reconstrucción de la memoria, es oportuno agregar la reflexión de Kaufman (1998), quien asevera que el testimonio es otra manera de trasmitir, actualizar, vincular tiempos y experiencias creando un nuevo espacio entre quien relata y quien escucha; como una forma de vincular el testimonio a la construcción y transmisión de la memoria.
De la misma manera como en los párrafos anteriores se ha reconocido el valor que tiene el relato como fuente del trabajo histórico, algunos autores también mencionan los cuidados o los peligros que se pueden correr si se hace un uso de los relatos orales de manera no rigurosa. Amaro (2011) alerta sobre la irrepresentabilidad que se puede presentar cuando situaciones históricas colapsan las relaciones entre experiencia y representación en un cliché, que, en lugar de marcar la diferencia de cada experiencia, la singularidad, planten una lógica totalizante. Por su parte, Chama (2006) alerta sobre lo que denomina los usos ingenuos de los testimonios por parte de quienes, desde un marcado sesgo empirista, se limitan a la mera trascripción de entrevistas; así como también a enfatizar el importante rol del investigador en la construcción y la interpretación de las fuentes orales. Peris Blanes (2005) alerta sobre el cuidado que hay que tener con una legitimación de la posición de enunciación del testigo, quien emerge como el portador de la verdad sobre el pasado por el hecho de haber visto o vivido tal o cual evento o experiencia.

En lo que tiene que ver con las narrativas, su reavivamiento como fuente histórica es producto del interés por escuchar la experiencia de quienes han padecido actos violentos $\mathrm{y}$ por el interés en la reconstrucción del relato histórico. "La narrativa es algo más que la simple configuración de relatos; es también un vehículo para la comprensión e interpretación de las personificaciones, de las relaciones entre los sujetos y de sentidos, contextualizados en el tiempo y en el espacio" (Ricoeur, citado por Lara, 2010, p. 360). Para Arfuch (2002), la narración se constituye en la mediación a través de la cual, la identidad singular no se pierde en la temporalidad, sino que se convierte en una historia que constantemente se significa y resignifica cada vez que se narra.

La emergencia de la narrativa como fuente histórica no es fortuita, está directamente relacionada con la emergencia de la historia cultural y la historia social, y dentro ellas ten- 
dencias como la microhistoria. María Paulinelli (2011) lo plantea de la siguiente manera:

La fragmentación identitaria y cultural como resultado de la emergencia de identificaciones étnicas y de las minorías en su vinculación con las diferencias, sumado a la permanencia de una percepción de descentramiento del sujeto, de las diversidades del mundo de la vida, de la multiplicidad de identidades y subjetividades, de la revalorización de los pequeños relatos con su pluralidad de voces, ha generado el reconocimiento de un espacio significante vinculado a la narrativa (p. 11).

Para Arfuch (2002), la importancia de la narrativa en el campo de las ciencias sociales aparece para dar cuenta, ajustadamente, de los procesos de auto creación, de las tramas de sociabilidad, de la experiencia histórica, situada, de los sujetos, en definitiva, de la constitución de identidades, individuales y colectivas. Según Paulinelli (2011), “contar la propia historia significa mostrar las huellas de los sucedido en la memoria, la configuración de la identidad individual o colectiva" (p. 3). Para esta autora, la configuración de la identidad individual y colectiva se vincula con la explotación de subjetividades y ancla su legitimidad en el reconocimiento de los sujetos y sus voces, voces que en la construcción de la memoria, hablan desde una conciencia social y política, además de mostrar inserción en la práctica social del relato como tal.

En esta misma línea argumentativa, Lara (2010) sugiere que la narrativa involucra no solo elaboraciones intelectuales, sino también, manifestaciones emocionales y afectivas que abarcan dimensiones personales, sociales y biográficas que son indisociables de las lógicas del decir, en otras palabras, del relato del sujeto, pues los relatos que la gente cuenta, hablan de lo que hacen, sintieron, les sucedió, o de las consecuencias que ha tenido la acción en un contexto determinado y en relación con los otros. Para Ricoeur (2001), cuando un sujeto se narra, emergen dos sentidos éticos: primero, la confrontación de sí mismo con lo que se ha vi- vido, y segundo, la emergencia de un compromiso moral individual y colectivo. De esta manera, cuando los sujetos se narran, se produce una conexión con la rememoración, facilitando que afloren dimensiones morales y políticas que contribuyen a la formación de subjetividades.

La identidad narrativa permite analizar justamente ese vaivén entre el tiempo de la narración y el tiempo de la vida, siguiendo a Ricoeur, María Eugenia Díaz (2010) define la identidad como un constructo narrativo que le permite al individuo definirse y construirse a sí mismo; la identidad adquiere una categoría práctica a través de la narración, pues narrar se convierte en una acción realizada por alguien que relata o representa su propia vida, que siempre está imbricada por la vida de los demás. En este sentido, los modos discursivos, narración y argumentación, son determinantes en la construcción identitaria de los sujetos, gracias al primero el sujeto se configura, se construye y se define a sí mismo a través del discurso narrado, pero además es configurado, representado, construido y definido por otros con los que se relaciona.

En conflictos como el colombiano, y también en otros ocurridos en diferentes lugares del mundo; el testimonio de los actores ha entrado a ocupar un lugar importante, no solo porque son la fuente principal para indagar sobre los acontecimientos de violencia, sino también, porque se ha producido un giro en la política pública, que les otorga un mayor posicionamiento a las víctimas en la agenda social. Herrera et al. (2014) demuestran que en el caso colombiano, acciones jurídicas como la que condujo a la creación del Centro de Memoria Histórica y los resultados de las investigaciones del grupo que lo dinamiza, han posicionado el interés por conocer y situar a las víctimas como objeto de reflexión y de política pública. En consecuencia con lo anterior, Castillejo (2000, citado por Herrera et al., 2014), subraya que la memoria tiene una fuerte relación con la narración, en tanto que permite cohesionar los relatos a través de los cuales los sujetos se leen. 
De este modo, la memoria fortalece el hilo a través del cual la experiencia humana deviene en relatos, conservando a pesar de la movilidad temporal del relato, rasgos en los cuales el sujeto se encuentra, se asimila, se narra, o se desconoce, modelando así procesos de subjetividad y de identificación colectiva (p. 53).

En los resultados de un trabajo realizado con población en condición de desplazamiento, Quintero y Ramírez (2009) concluyen que la narración aparece como una categoría metodológica y teórica, necesaria para penetrar en la experiencia y el mundo subjetivo de las personas; la narración dota a los sujetos que narran, de una función política importante frente al olvido y el reconocimiento del pasado, para que las historias de barbarie no se repitan. En posición coincidente con Castillejo (2000), Quintero y Ramírez (2009) plantean que, a través de las narraciones, los sujetos otorgan sentido a lo ético y lo político en contextos de violencia: "La narración se establece como punto nodal para la comprensión de la personalidad moral y de la subjetividad política, llegando al punto de la deshumanización donde se destruye toda libertad y solidaridad entre los seres humanos, pero además, su posibilidad de ser sujeto agente de iniciativas sociales y políticas" (p. 57). Si bien es cierto que los investigadores pueden incurrir en acciones de revictimización como las ya mencionadas. Trabajos como los anteriormente citados destacan la potencia que ciertas apuestas investigativas, y su posibilidad de generar ejercicios de reconstrucción de memoria, en cuanto tengan la capacidad de constituirse como facilitadores de testimonios, promuevan la emergencia de subjetividades políticas individuales y colectivas.

\section{Conclusión: memoria, violencia y construcción de subjetividades}

Si se piensa en fenómenos violentos traumáticos y de profundo impacto para las víctimas, su comunidad y la sociedad en general por la violencia desencadenada, se contempla la memoria como una expresión de la conciencia y de la subjetividad que le permite a cada uno definirse, ubicarse y reconocerse ante su pasado (en la historicidad) y ante sus semejantes (en la alteridad). La memoria se constituye así como parte de la museología contemporánea, que lleva a cabo un trabajo en torno a la exposición, para permitir a los hombres producir configuraciones y reconfiguraciones de su existencia (Gaulejac \& Silva, 2002). Para Halbwachs (2004), la memoria está ligada a la percepción, de manera que el recuerdo remite necesariamente a la vida colectiva y cualquier acto de percepción entraña en sí mismo una conmemoración. La memoria da cuenta de la experiencia social vivida, de manera que lo que perdura es aquello que se inscribe en una trama narrativa de conjunto que posibilita la construcción social de significaciones y simbolizaciones mutuamente reconocidas en un contexto social determinado.

En su trabajo sobre los abusos de la memoria, Todorov (2000) argumenta que el acontecimiento vivido puede ser leído de manera literal o de manera ejemplar. Es preservado en su literalidad cuando permanece intransitivo y no conduciendo más allá de sí mismo. La persona subraya las causas y consecuencias de un acto, determina los participantes en él y sus acciones, estableciendo además una continuidad entre el ser que fue y el que es ahora, extendiendo las consecuencias de acto de violencia a todas las instancias de la existencia. La experiencia se convierte en ejemplar, cuando sin negar la singularidad del suceso, la persona decide utilizarlo para comprender situaciones nuevas. Por una parte, la situación dolorosa se controla y se margina, y por la otra, se narra; y en este momento deja de ser privada y entra en la esfera pública, abriendo el recuerdo a la analogía y la generalización. En ese momento el pasado se convierte en principio de acción para el presente, se ha constituido un proceso de subjetivación.

Cuando estamos frente a la reconstrucción de memoria de acontecimientos violentos, el encuentro de múltiples relatos contenidos en las narrativas de las víctimas, "los victimarios, 
los investigadores, los actores sociales; se constituyen en una herramienta que propicia la reconstrucción de la unidad social fragmentada por la violencia" (Springer, 2002, p. 133). Así, se vislumbra como un escenario fecundo para el rescate de las visiones compartidas, de los vínculos que se mantienen y que emergen por los efectos de la violencia. En palabras de Todorov (2000), la puesta en común de los relatos y el reconocimiento social de sus gramáticas opera más allá de lo verbal y penetra en el paisaje permitiendo que la memoria adquiera un carácter ejemplar: un talante ético político sobre el presente, que irradia aprendizajes para reemprender un camino socialmente viable.

La violencia experimentada en países como Sudáfrica y Argentina ha conducido a que diferentes sectores destinen grandes energías en la construcción de relatos nacionales que incluya su experiencia traumática y haga justicia a las víctimas. Esto obedece según Cabrera (2006), a que la memoria traumática vive un proceso de expansión y se ha convertido en un punto central en las reivindicaciones políticas de grupos sociales en todo el mundo. Para Elsa Blair (2002), se han encontrado por los menos tres caminos por los cuales se puede avanzar en el proceso de sanar heridas abiertas en los seres y en las sociedades: la puesta en escena pública del dolor (reconocimiento y discurso político de los dirigentes); la conmemoración histórica para recrear resignificando ese dolor y la puesta en palabras de ese dolor a través de relatos y testimonios.

Si bien se ha considerado como factor importante visibilizar los hechos de violencia y principalmente a las víctimas, igual de importante es resaltar los procesos de elaboración y recuperación de los acontecimientos traumáticos. En palabras de Blair (2002), "las experiencias aterradoras se pueden integrar en las historias de vida como una manera de aportar a una redención colectiva e individual, además de dar fortaleza y capacidad de recuperación" (p. 15). Para Beatriz Sarlo (2002) la rememoración puede devolver la confianza a la persona que narra su vida y en última instancia reparar una identidad lastimada.

En el trabajo titulado Recordar y narrar el conflicto, el Grupo de Memoria Histórica (2011) reflexiona sobre el papel que pueden jugar ciertas formas de enunciación en la construcción de subjetividades; sostienen que algunos gestores y gestoras de memoria, prefieren el término "sobreviviente" bajo el argumento de que, a las víctimas a menudo solo se les pregunta por la manera como fueron victimizadas y sus historias de dolor. Uno de los problemas reside en que al posicionarse como víctima puede llevar a silenciar otras historias o aspectos de su experiencia, y no abrir lugar para historias de cómo han sobrevivido; para sus historias de resiliencia, restablecimiento y resistencia.

Los resultados de los trabajos realizados por Riaño (2006) con jóvenes de Medellín, enfatizan en que la subjetividad se configura en la medida en que al recordar y olvidar, se le da sentido a lo acontecido, se le da reconocimiento a la manera de ser de cada sujeto, se le permite definirse, formar su identidad. Desde esta perspectiva, los procesos de subjetividad están directamente relacionados con ejercicios de rememoración, en cuales los sujetos elaboran los referentes simbólicos que dan sentido y significado a las prácticas que han sido constitutivas de su identidad.

En el marco de la reflexión, memoria, violencia y construcción de subjetividades, la narración ocupa un lugar central, puesto que el relato opera como detonante de la subjetivación (Ricoeur, citado por Lara, 2010). Desde esta óptica, para Arfuch (2002), por el lenguaje el hombre se constituye como sujeto, y su subjetividad entra en juego por medio de la capacidad de expresión para plantearse como tal, como sujeto que emerge por medio del lenguaje. Lara (2010) pone la discusión en los siguientes términos:

Al narrar una historia se configuran procesos de subjetivación referidos no solo a una 
biografía personal, sino también a una vida contextualizada en las culturas y que la subjetividad ligada a la narración implica una subjetividad vulnerable a interpretaciones que transfiguran al sujeto en sujeto de comprensión, en sujeto de interpretación, en sujeto de construcción (p. 363).

Un estudio realizado por Arroyave y Tabares (2010) con víctimas del conflicto armado en Medellín, señala entre sus conclusiones que el devenir entre el sujeto doliente y el sujeto político, es un tránsito de ida y vuelta que se presenta constantemente en la vida cotidiana de las víctimas, no como un proceso acabado e inequívoco, sino que es vivenciado de forma articular por cada víctima. Se ancla en la experiencia de victimización caracterizada por el dolor que es el eje articulador de las vivencias comunes a todas las víctimas y protagonista principal que le otorga cualidades como sujeto doliente. Genera crisis en los referentes hasta ahora existentes y repliegue del sujeto. La potencia de la víctima se encuentra en la posibilidad de trascender de su intimidad sufriente, mediante procesos reflexivos frente a su experiencia de victimización que permiten la reinterpretación y actualización de su mundo de sentido, interpelado a otros en lo público como sujeto moral, para posibilitar el despliegue del sujeto político. En este orden de ideas, la subjetividad entonces se reconfigura en un permanente diálogo entre el afuera comprendido como el contexto sociopolítico y el adentro comprendido como la esfera más íntima de nuestro ser.

\section{Notas}

${ }^{1}$ En el acontecimiento al que se hace mención murieron 79 personas y decenas resultaron heridas como consecuencia de la explosión en el centro religioso local de un cilindro bomba lanzado por las Fuerzas Armadas Revolucionarias de Colombia, FARC, en su confrontación con los paramilitares. Centro Nacional de Memoria Histórica (2010, p. 13).

\section{Referencias}

Amaro, L. (2011). Algunas ideas sobre subjetividad, escritura, silencio. Analecta. Revista de Humanidades, 5, 17-127. Recuperado de https://dialnet.unirioja.es/ servlet/articulo? codigo $=3984582$.

Arfuch, L. (Comp.) (2002). Problemáticas de la identidad. En, Identidades, sujetos y subjetividades (pp. 21-44). Buenos Aires: Prometeo Libros.

Aróstegui, J. (2004). La historia vivida. Sobre la historia del presente. Madrid: Editorial Alianza.

Arroyave, D., \& Tabares C. (2010). Las víctimas del conflicto armado y su devenir en sujeto político (Tesis de maestría). Alianza CINDE - Universidad de Manizales, Colombia.

Aurell, J. (2006). La función social de la memoria. En R. Alvira, H. Ghiretti \& M. Herrero (Eds.), La experiencia social del tiempo (pp. 149-170). Pamplona: Ediciones Universidad de Navarra.

Blair, E. (2002). Memoria y narrativa: La puesta del dolor en la escena pública. Revista Estudios Políticos, 21, 9-28.

Cabrera, M. (2006). Exceso y defecto de la memoria: violencia política, terror, visibilidad e invisibilidad. Revista Oasis, 11, 39-55.

Castillejo, A. (2000). Poética del otro. Antropología de la guerra, la soledad y el exilio interno en Colombia. Bogotá: Colciencias; Ministerio de Cultura.

Castillejo, A. (2005). Las texturas del silencio: violencia, memoria y los límites del quehacer antropológico. EMPIRIA. Revista Metodológica de Ciencias Sociales, 9, 39-59. 
Centro Nacional de Memoria Histórica. (2010). Bojayá la guerra sin límites. Bogotá: Ediciones Semana; Taurus.

Centro Nacional de Memoria Histórica \& University of British Columbia. (2011). Recordar y narrar el conflicto. Herramientas para reconstruir la memoria histórica. Colombia: Imprenta Nacional.

Chama, M. (2006). El lugar de las fuentes orales en la comprensión del pasado reciente. Revista Sociohistórica, 19-20, 217-222. Recuperado de http://www.sociohistorica.fahce.unlp.edu.ar/article/view/SHn19$20 \mathrm{a} 10$

Cosci, L. (2011). Caminos de rememoración. La memoria y la construcción del conocimiento histórico en la hermenéutica Paul Ricoeur. Cifra, 6, 29-40.

Cuesta, J. (1993). Historia del presente. Madrid: Eudema.

Cuesta, J. (Ed.) (1998). Memoria e Historia. Un estado de la cuestión. En, ayer (pp. 203-246). Madrid: Marcial Pons. Recuperado de http://cesycme.co/wp-content/ uploads/2015/07/memoria-e-historia-unestado-de-la-cuesti\%C3\%B3n.pdf

Díaz, M. (2010). Construcción de la identidad por medio del discurso. Cifra, 5, 127131. Recuperado de http://fhu.unse.edu. ar/carreras/rcifra/c5/cotacio.pdf

Franco, M., \& Levín, F. (Comps.) (2007). El pasado cercano en clave historiográfica. En, Historia reciente. Perspectivas y desafios para un campo en construcción (pp. 31-65). Buenos Aires: Paidós.

Gaulejac, V., \& Silva H. (2002). Memoria e historicidad. Revista Mexicana de Sociología, 64(2), 31-46. Recuperado de http:// methesis.fcs.ucr.ac.cr/blogs/abonilla/wp-
content/uploads/2011/03/Gaulejac-Vincent-de-Memoria-e-historicidad.pdf

Halbwachs, M. (2004). Los marcos sociales de la memoria. Barcelona: Anthropos.

Herrera, M., Ortega, P., Cristancho J., \& Olaya, V. (2014). Memoria y formación: configuraciones de la subjetividad en ecologías violentas. Bogotá: Universidad Pedagógica Nacional.

Hirch, L., \& Díaz V. (2010). Entre el olvido y la memoria. La construcción discursiva de las víctimas de la última dictadura militar en Argentina en el diario puntal en la década del 90. Revista Perspectivas de la Comunicación,3(2), 107-124. Recuperado de publicacionescienciassociales.ufro.cl/ index.php/perspectivas/article/.../81

Hobsbawm, E. (2005). Desafio de la razón. Manifiesto para la renovación de la historia. Santiago de Chile: Centro de Estudios Miguel Enríquez.

Husson, J. (2000). Historia y memoria de las dos guerras mundiales. ¿Educar en la memoria? Reims: Centro regional de documentación pedagógica Champagne-Andenne.

Huyssen, A. (1999). La cultura de la memoria: medios, política, amnesia. Revista de Crítica Cultural, 18, 8-15.

Jaramillo, J. (2010). La reconstrucción de la memoria histórica del conflicto colombiano en el actual proceso de Justicia y Paz. Alcances, desafíos y preguntas. Desafios, 22(2), 31-70.

Jelin, E. (2002). Los trabajos de la memoria. Madrid: Siglo XXI Editores.

Jelin, E. (2003). Los Derechos Humanos y la memoria de la violencia política y la represión: la construcción de un campo 
nuevo en las ciencias sociales. Cuadernos del IDES, 2, 1-27. Recuperado de http:// ides.org.ar/wp-content/uploads/2012/03/ cuaderno2_Jelin.pdf

Kaufman, S. (1998, noviembre). Sobre violencia social, trauma y memoria. Seminario: Memoria Colectiva y Represión. Montevideo, Uruguay.

Koselleck, R. (2006). Historia conceptual, memoria e identidad. Entrevista realizada por Javier Fernández Sebastián / Juan Francisco Fuentes. Revista de Libros, 112.

La Capra, D. (2001). Historia y escritura, escritura y trauma. Baltimore: Johns Hopkins University Press.

Lara, L. (2010). Potencial de las narrativas en la investigación de subjetividades de las y los jóvenes desvinculados de los grupos alzados en armas, en su proceso de integración a la vida civil. Magis. Revista Internacional de Investigaciones en Educación, 2(4), 357-370.

Le Goff, J. (1991). El orden de la memoria. El tiempo como imaginario. Paidós: Barcelona.

Montoya, V., \& Arango, G. (2008). Territorios visuales del tiempo y la memoria. Exploraciones metodológicas en la vereda Mogotes del municipio de Buriticá. Boletín de Antropología de la Universidad de Antioquia, 22(39), 185- 206.

Mudrovcic, M. (2005). Historia, Narración y Memoria, debates actuales en filosofía de la Historia. Madrid: AKAL.

Olick, J. (1998). Memoria colectiva y diferenciación cronológica: historicidad y ámbito público. En J. Cuesta (Comp.), Memoria e historia (pp. 119-146). Madrid: Editorial Marcial Pons.
Paulinelli, M. (2011, noviembre). Los relatos de la memoria en Córdoba (2010-2011). Significaciones. Posibilidades discursivas. Encuentro internacional: Fecundidad de la memoria. Desafíos del presente a los usos del pasado en América Latina. Córdoba, Argentina.

Pécaut, D. (2003). Memoria imposible, historia imposible, olvido imposible. En Violencia y política en Colombia. Elementos de reflexión. Universidad del Valle: Hombre Nuevo.

Peris, J. (2005). La imposible voz. Memoria $y$ representación de los campos de concentración en Chile: La posición del testigo. Santiago de Chile: Editorial Cuarto Propio.

Quintero,M.,\&Ramírez,J.(2009).Narraciones, memorias y ciudadanía. Desplazamiento forzado. Bogotá: Universidad Distrital Francisco José de Caldas; Instituto para la Pedagogía, la Paz y el Conflicto Urbano (IPAZUD).

Riaño, P. (2006). Jóvenes, memoria y violencia en Medellín. Una antropología del recuerdo y el olvido. Medellín: Universidad de Antioquia; Instituto Colombiano de Antropología.

Richard, N. (2002) La crítica de la memoria. Revista Cuadernos de Literatura, 8(15), 187-193.

Ricoeur, P. (2000). Historia y memoria. La escritura de la historia y la representación del pasado. Recuperado de http://www. historizarelpasadovivo.cl/downloads/ ricoeur.pdf.

Ricoeur, P. (2001). Del texto a la acción. Ensayos de Hermenéutica II. Argentina: Fondo de Cultura Económica. 
Ricoeur, P. (2010). Tiempo y narración. México: Siglo XXI Editores.

Sarlo, B. (2005). El tiempo pasado. Cultura de la memoria y giro subjetivo. Una discusión. Buenos Aires: Siglo XXI Editores.

Schwarzstein, D. (2002). Memoria e historia. Revista de Ciencias Sociales, 42(167), 469-482.

Schwarzstein, D. (2010). Fuentes orales en los archivos. Desafíos y problemas. Revista Historia de la antropología y las fuentes orales HAFO, 3(27), 167-177.

Serna, A. (2009). Memorias en crisoles: propuestas teóricas, metodológicas, y estratégicas para los estudios de la memoria. Bogotá: Universidad Distrital Francisco José de Caldas; Centro de memoria, paz y reconciliación Distrital.

Springer, N. (2002). Sobre la verdad en los tiempos de miedo. Del establecimiento de una comisión de la verdad en Colombia y los desafios para una justicia restaurativa. Bogotá: Universidad Externado de Colombia.
Tafalla, M. (1999). Primo Levi y la razón anamnética. Revista internacional de la razón teórica y práctica, 30, 89-97. Recupero de http://www.raco.cat/index.php/enrahonar/article/viewFile/31972/31806

Tébar, J. (2006). Biografías, autobiografías y testimonios por la memoria de la represión franquista. Revista de historia contemporánea, 6, 776-791. Recuperado de http://hispanianova.rediris.es/6/HISPANIANOVA-2006.pdf

Todorov, T. (2000). Los abusos de la memoria. Barcelona: Paidós.

Traverso, E. (2007). El pasado, instrucciones de uso. Historia, memoria y política. Bogotá: Marcil Pons.

Torres, J. (2015). Las memorias públicas sobre el conflicto colombiano. Perspectiva analítica desde los centros de memoria (Tesis de pregrado). Universidad del Rosario, Bogotá, Colombia.

Yerushalmi, Y. (1998). Reflexiones sobre el olvido. En Y. Yerushalmi, N. Loraux, J. Milner \& G. Vattimo, Usos del olvido (pp. 13-26). Buenos Aires: Editorial Nueva Visión. 
